\title{
A rare case report of sirenomelia
}

\section{Kumar A. ${ }^{1}$, Snehlata ${ }^{2}$, Srivastava M. $^{3}$}

${ }^{1}$ Dr. Abhishek Kumar, General Surgery, ${ }^{2}$ Dr. Snehlata, ${ }^{3}$ Dr. Manjula Srivastava, HOD \& Associate Professor Department of Obstetrics \& Gynaecology, HMCH, Hazaribagh, Jharkhand, India; 1,2authors are Specialist Doctor at Sadar Hospital, Hazaribagh \&Visiting Consultant at Vandana Nursing Home, Shivpuri, Hazaribag, Jharkhand, India.

Corresponding Author: Dr. Snehlata, Specialist Doctor at Sadar Hospital, Hazaribagh \& Visiting Consultant at Vandana Nursing Home, Shivpuri, Hazaribag, Jharkhand, India. E-mail: sneha91@ymail.com

\begin{abstract}
Mermaid syndrome is a rare congenital fetal anomaly with characteristic feature of complete or partial fusion of lower limbs. Although, this syndrome is incompatible with life due to the association of several congenital defect and malformation. In our case Patient was a 31.3 week. A $1.1 \mathrm{~kg}$, preterm infant of unidentified sex was born, a live born, normally delivered at preterm by a 25 -year-old primigravida of lower socioeconomic status. Examination of the baby revealed caudal dysgenesis having apparent fusion of the legs into a single lower limb the most severe form, only a single bone is present,with no indication of legs or feet. There was no identifiable external genitalia and anus. Incidentally the infant died after 45 minutes post birth and we report this case due to their rarity and preterm live birth.
\end{abstract}

Keywords: Caudal regression syndrome, Mermaid syndrome, Potter's facies, Sirenomelia

\section{Introduction}

Sirenomelia is also known as Mermaid Syndrome is a rare and fatal congenital defect and malformation of uncertain etiology. characterized by varying degrees of lower limb fusion, thoracolumbar spinal anomalies, sacrococcygeal agenesis, genitourinary, and anorectal atresia[1]. The incidence of sirenomelia is $0.8-1$ case/100,000 live births with male to female ratio being 3:1 [2]. It is usually fatal within a day or two of birth because of complications associated with abnormal kidney and urinary bladder development and function. There is a strong association with maternal diabetes where relative risk is $1: 200-250$ and up to $22 \%$ of fetuses with this anomaly will have mothers with diabetes [3,4]. The rarity of the case is obvious from the fact that many a gynecologist might not have come across a case of sirenomelia in their whole professional carrier. The disorder was thought to be an extreme case of Caudal Regression Syndrome (CRS), however it was classified to be considered a separate condition.

Table 1: Differentiation of signs in CRS and Sirenomelia.

\begin{tabular}{|c|c|c|}
\hline Sign & CRS & Sirenomelia \\
\hline Umbilical artery & Two & One \\
\hline Lower limb & Two hypoplastic & Single or fused \\
\hline Renal anomalies & Non lethal & Agenesis \\
\hline Anus & Imperforate or N & Absent \\
\hline Amniotic fluid & Polyhydramnios or N & Oligohydramnios \\
\hline
\end{tabular}

\section{Case report}

25-year-old Primigravida admitted with 7-month amenorrhoea, Her period of gestation was 31 weeks 3 days. Perceiving fetal movements well, registered outside, with lower socioeconomic status, immunized. She was otherwise healthy with no known history of genetic or congenital anomaly in her family. She had uneventful antenatal period till admission when she presnted in active labour.

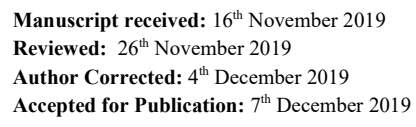




\section{Case Report}

On examination patient was poorly built and malnourished. Her height was $141 \mathrm{~cm}$ and weight was only $41 \mathrm{~kg}$. She was conscious, oriented, Respiratory \& cardiovascular examination were normal. No signs of pallor, cyanosis, clubbing and oedema were observed. P/A-on inspection abdomen was globular, umbilicus was central and everted. Striae gravidarum and linea nigra were present. On palpation uterus was 28 weeks with regular fetal heart rate, external ballottement present, $\mathrm{P} / \mathrm{V}-\mathrm{Os}$ was $3-4 \mathrm{~cm}$ dilated, fully effaced, BOM forming, station ' 0 , presentation was cephalic.

She delivered a preterm baby with weight was $1.1 \mathrm{Kg}$, with multiple congenital anomalies. The Apgar score was 3 at 1 ' and 0 at $5 \mathrm{~min}$.

The baby died within 45 min post birth in spite of resuscitation attempts by neonatologist. On physical examination, the bilateral hypoplastic thumb, birth defect of the lower body characterized by the apparent fusion of the legs into a single lower limb the most severe form. Only a single bone is present, with no indication of legs or feet with absent external genitalia, and umbilical cord with single umbilical artery [Figure 1a].

There were also prominent epicanthal folds, downward curved nose, receding chin, low-set soft dysplastic ears and small slit-like mouth suggestive of Potter's facies [Figure 1b]. Autopsy was declined by the parents. Intrapartum and the postpartum period of mother was uneventful.

Investigations: Hb-11.9, Tlc-10,200, Platelet-1,62,000, RBS-76, BG-O Positive, HbsAg-negative, HIV-Non-reactive, VDRL-Non reactive, USG-Single live intrauterine foetus of 25 weeks 6days with cephalic presentation with severe 238ligohydramnios with bilateral renal agenesis.
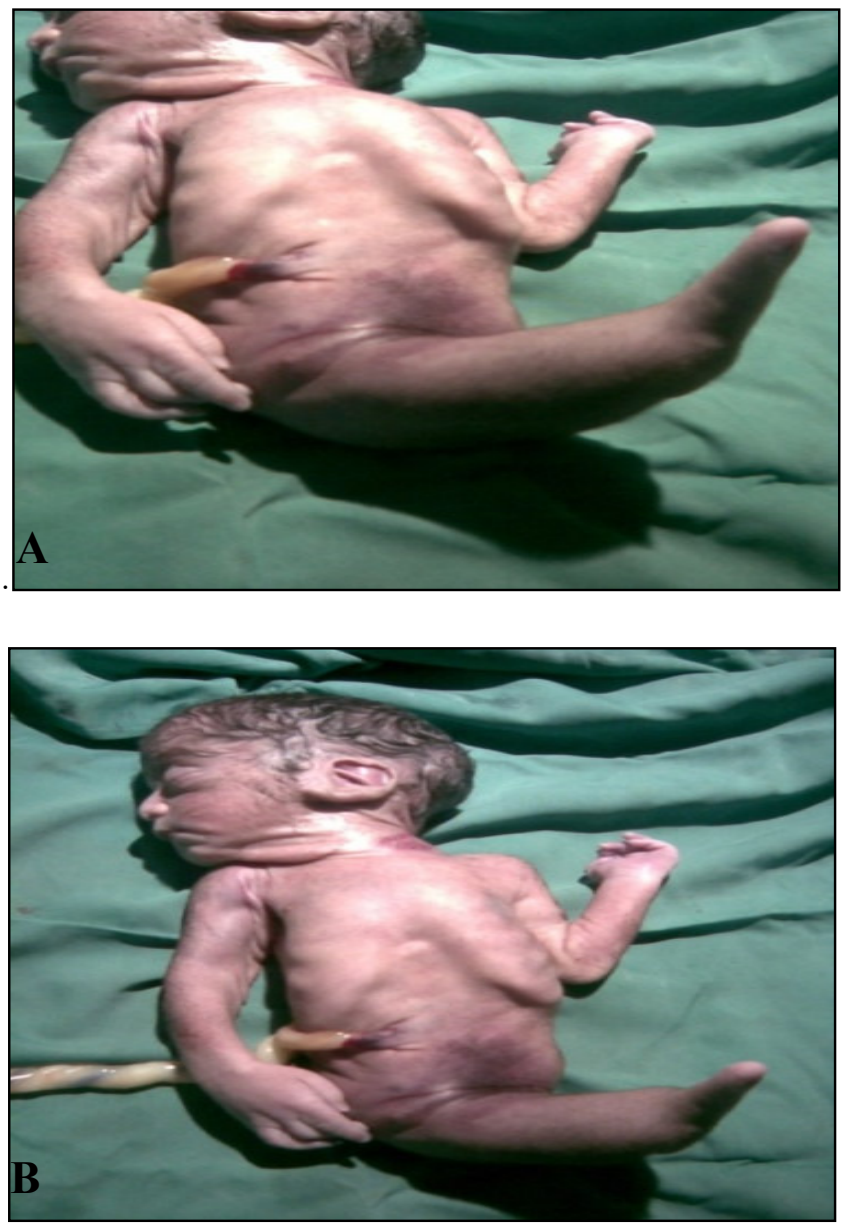

Fig-1-A,B: Photograph of the baby showing birth defect of the lower body characterized by the apparent fusion of the legs into a single lower limb, hypoplastic thumb, absent external genitalia and features of Potter's facies (prominent epicanthal folds, small slit-like mouth, receding chin, downward curved nose, and low-set soft dysplastic ears). 


\section{Case Report}

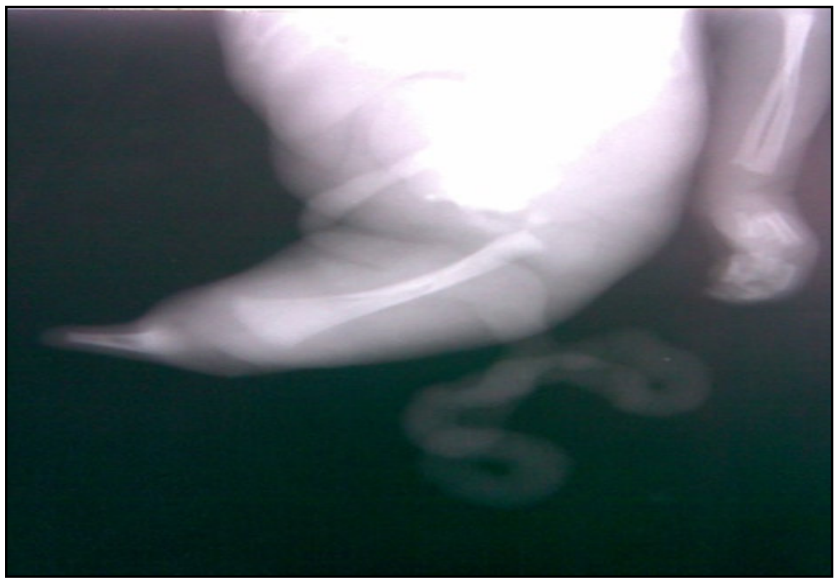

Fig-2: X-Ray lower abdomen showing single limb with rudimentary lower limbs bone with no anal opening.

\section{Discussion}

Anomalies observed in sirenomelia are described as the most severe form of caudal regression syndrome [5]. Fusion of the lower extremities, presence of single umbilical and persistent vitelline artery are major features of sirenomelia [6].

Although the primary molecular defect resulting in sirenomelia remains unclear, two main pathogenic hypotheses namely the vascular steal hypothesis and the defective blastogenesis hypothesis are proposed. According to vascular steal hypothesis [7] fusion of the limbs results from a deficient blood flow and nutrient supply to the caudal mesoderm, which in turn results in agenesis of midline structures and subsequent abnormal approximation of both lower limb fields.

However in defective blastogenesis hypothesis [8] the primary defect in development of caudal mesoderm is attributed to a teratogenic event during the gastrulation stage. Such defect interferes with the formation of notochord, resulting in abnormal development of caudal structures. Maternal diabetes, tobacco use, retinoic acid and heavy metal exposure are possible environmental factors [9]. In our case, there was no history of tobacco use and diabetes before and during pregnancy.

Sirenomelia is usually fatal within a day or two of birth because of complications associated with abnormal kidney and urinary bladder development and function. In literature approximately 300 cases [5] are reported worldwide of which 14 are from India.

In most of the cases the diagnosis was performed after birth. In antenatal period, sirenomelia can be diagnosed as early as 13 weeks by using high resolution or colour Doppler sonography $[10,11]$. The condition is usually incompatible with life due visceral abnormalities especially that of renal system. Exceptional cases without renal agenesis have survived, the best example being Tiffany Yorks, a 13-year-old girl who was born with fused legs.

Over the years, she has undergone numerous operations to separate her lower extremities [12].

The facial abnormality usually found in sirenomeliac infants known as Potter's facies, which includes large, low-set ears, prominent epicanthic fold, flat nose and receding chin. In our case, features of Potter's facies were present. When features of Potter's facies are combined with oligamnios and pulmonary hypoplasia it is known as Potter's syndrome [13] which was present in our case. In our case, the right thumb was hypoplastic, which was also previously reported [14].

Stocker and Heifetz classified Sirenomeliac infants from Type I to Type VII according to the presence or absence of bones within the lower limb [15]. Although we did have radiographs to classify our case with certainty and based on external examination, we suggest our case belonged to Type VII, the most severe form, only a single bone is present, with no indication of legs or feet. Birth defect of the lower body characterized by the apparent fusion of the legs into a single lower limb.

\section{Conclusion}

Sirenomelia is a rare and lethal congenital anomaly. When diagnosed antenatally, termination should be offered. However, prevention is possible and should be the goal. Regular antenatal check up with optimum maternal blood glucose level in pre-conceptional period and in first trimester should be maintained to prevent this anomaly. 


\section{Case Report}

\section{References}

1. Valenzano M, Paoletti R, Rossi A, Farinini D, Garlaschi G, Fulcheri E. Sirenomelia. Pathological features, antenatal ultrasonographic clues, and a review of current embryogenic theories. Hum Reprod Update. 1999; 5(1):82-86. doi: 10.1093/humupd/5.1.82.

2. Reddy KR, Srinivas S, Kumar S, Reddy S, Hariprasad Irfan GM. Sirenomelia a rare presentation. J Neonatal Surg. 2012;1(1):7. eCollection 2012 Jan-Mar.

3. Aslan H, Yanik H, Celikaslan N, Yildirim G, Ceylan Y. Prenatal diagnosis of Caudal regression syndrome: A case report. BMC Pregn Childbirth. 2001;1:8. doi:10. 1186/1471-2393-1-8.

4. González-Quintero VH, Tolaymat L, Martin D, Romaguera RL, Rodríguez MM, Izquierdo LA. Sonographic diagnosis of caudal regression in the first trimester of pregnancy. J Ultrasound Med. 2002;21(10): 1175-1178. doi: https://doi.org/10.7863/jum. 2002. 21.10.1175.

5. Duhamel B. From the Mermaid to Anal Imperforation: The syndrome of Caudal regression. Arch Dis Child. 1961;36:152-155. doi: 10.1136/adc.36. 186.152.

6. Twickler D, Budorick N, Pretorius D, Grafe M, Currarino G. Caudal regression versus sirenomelia: Sonographic clues. J Ultrasound Med. 1993;12(6):323330. doi: https://doi.org/10.7863/jum.1993.12.6.323.

7. Sadler TW, Rasmussen SA. Examining the evidence for vascular pathogenesis of selected birth defects. Am J Med Genet A. 2010;152A(10):2426-2436. doi: https:// doi. org/ 10.1002/ajmg.a.33636.
8. Duesterhoeft SM, Ernst LM, Siebert JR, Kapur RP. Five cases of caudal regression with an aberrant abdominal umbilical artery: Further support for a caudal regression-sirenomelia spectrum. Am J Med Genet A. 2007;143A(24):3175-3184.doi: https://doi.org/10. 1002/ ajmg.a.32028.

9. Naveena S, Mrudula C. Sirenomelia -The mermaid syndrome: A case report. IOSR J Dent Med Sci. 2013; $7: 1-4$.

10. Vijayaraghavan SB, Amudha AP. High-resolution sonographic diagnosis of sirenomelia. J Ultrasound Med. 2006;25(4):555-557. doi: https://doi.org/10. 7863/ jum. 2006.25.4.555.

11. Sahu L, Singh S, Gandhi G, Agarwal K. Sirenomelia: A case report with literature review. Int J Reprod Contracept Obstet Gynecol. 2013;2(3):430-432. doi: 10.5455/2320-1770.ijrcog20130936.

12. Shah DS, Tomar G, Preetkiran Sirenomelia. Indian J Radiol Imaging. 2006; 16(2):203-204.

13. Dharmraj M, Gaur S. Sirenomelia: A rare case of foetal congenital anomaly. J Clin Neonatol. 2012;1(4): 221-223. doi: 10.4103/2249-4847.106006.

14. Banerjee A, Faridi MM, Banerjee TK, Mandal RN, Aggarwal A. Sirenomelia. Indian J Pediatr. 2003;70(7): 589-591.

15. Stocker JT, Heifetz SA. Sirenomelia. A morphological study of 33 cases and review of the literature. Perspect Pediatr Pathol. 1987;10:7-50.

\section{How to cite this article?}

Kumar A, Snehlata, Srivastava M. A rare case report of sirenomelia. Obs Rev: J Obstet Gynecol 2019;5(5): 237-240. doi:10.17511/joog.2019.i05.05. 